Rochester Institute of Technology

RIT Scholar Works

Presentations and other scholarship

Faculty \& Staff Scholarship

Spring 4-25-2020

\title{
Completing A Crowdsourcing Task Instead Of An Assignment; What Do University Students Think?
}

Javed-Vassilis Khan

Eindhoven University of Technology

Konstantinos Papangelis

Rochester Institute of Technology

Panos Markopoulos

Eindhoven University of Technology

Follow this and additional works at: https://scholarworks.rit.edu/other

Part of the Other Computer Sciences Commons

\section{Recommended Citation}

Khan JV, Papangelis K, Markopoulos P.Completing A Crowdsourcing Task Instead Of An Assignment; What Do University Students Think?. Case Study. 30th ACM Conference on Human Factors in Computing Systems (CHI'20). ISBN: 978-1-4503-6819-3/20/04. Doi: https://doi.org/10.1145/3334480.3375228.

This Conference Paper is brought to you for free and open access by the Faculty \& Staff Scholarship at RIT Scholar Works. It has been accepted for inclusion in Presentations and other scholarship by an authorized administrator of RIT Scholar Works. For more information, please contact ritscholarworks@rit.edu. 


\section{Completing A Crowdsourcing Task Instead Of An Assignment; What Do University Students Think?}

Vassilis-Javed Khan

Eindhoven University of Technology

Eindhoven, The Netherlands

v.j.khan@tue.nl

Konstantinos Papangelis

Rochester Institute of Technology

Rochester, NY, USA

Kpapangelis@me.com

Panos Markopoulos

Eindhoven University of Technology

Eindhoven, The Netherlands

p.markopoulos@tue.n
Permission to make digital or hard copies of part or all of this work for personal or classroom use is granted without fee provided that copies are not made or distributed for profit or commercial advantage and that copies bear this notice and the full citation on the first page. Copyrights for third-party components of this work must be honored. For all other uses, contact the owner/author(s)

CHI'20 Extended Abstracts, April 25-30, 2020, Honolulu, HI, USA (c) 2020 Copyright is held by the owner/author(s).

\begin{abstract}
University educators actively seek realistic projects to include in their educational activities. However, finding an actually realistic project is not trivial. The rise of crowdsourcing platforms, in which a variety of tasks are offered in the form of an open call, might be an alternative source to help educators scale up projectbased learning. But how do university students feel about executing crowdsourcing tasks instead of their typical assignments? In a study with 24 industrial design students we investigate students' attitudes on introducing crowdsourcing tasks as assignments. Based on our study we offer four suggestions to universities that consider integrating crowdsourcing tasks in their educational activities.
\end{abstract}

\section{Author Keywords}

Project based learning; crowdsourcing; university students' attitude; higher education.

\section{CSS Concepts}

- Human-centered computing Human computer interaction (HCI); User studies. 


\section{Introduction}

Educators actively seek the involvement of external parties in their educational activities to increase the relevance of teaching to society, motivate students and enrich course content. Whether it is a guest lecture from an industry expert, a project inspired by an industrial context, a hackathon, or an internship, all are sought after activities for both students and teachers alike. However, looking for, convincing, and engaging an external party to work with students in higher education is far from trivial.

Crowdsourcing (CS) platforms, are a novel form of websites that offer work, mostly in exchange for money. Usually, contributors, commonly referred to as "workers", compete to get the prize, usually monetary, associated with the work. There are currently hundreds of different platforms (a partial list can be found at: http://vjkhan.com/projects/list-of-crowdsourcingplatforms.html) that offer thousands of tasks. Since tasks are already publicly available online, there is a unique opportunity to utilize them in educational activities.

In this study we set out to investigate what are the attitudes of university students when it comes to integrating crowdsourcing tasks into educational activities. More specifically, we conducted in-depth interviews with 24 industrial design students. Our main finding is that overall students are quite enthusiastic about the concept. This enthusiasm though creates expectations that university-level educators need to manage. We conclude this case study by suggesting what educational institutes need to do, to successfully integrate crowdsourcing tasks as educational assignments in their curricula.

\section{Background}

Project-based learning (PBL) is a comprehensive approach to engage students with authentic problems that they can learn from [1]. PBL crucially tries to integrate learning with the students' intrinsic motivation by placing them in realistic and contextualized problems that they have to analyze, understand and eventually develop a solution. This is a crucial dimension of PBL; namely the projects' realism. In other words, the projects that students engage should not be "school like" [11].

PBL's effectiveness and advantages include (among others): decreasing the achievement gap by benefitting low performing students to a greater extent than high performing ones [5]; facilitating team communication and stimulating collaborative behavior [12]; obtaining content knowledge and group work skills [9].

Challenges to implement PBL include finding "authentic" projects [4] and selecting them [6]. Furthermore, cases in which results have not been positive was when teachers developed non-problem-focused projects [11].

Although PBL has been widely applied and researched, crowdsourcing platforms offer a new pool of potential realistic projects. The novelty in leveraging crowdsourcing compared to traditional PBL is that: 1) teachers can now have a plethora of projects to choose from; 2) tasks are realistic -actual individuals or companies request them; 3 ) students can share the project output to an online, public website; 4) platforms offer a monetary reward for the completion of tasks. For the aforementioned reasons, more recently researchers have started to investigate the potential 


\section{Structure of our Proposal}

Each proposal for replacing

an existing course

assignment with an existing

crowdsourcing task was

structured in the form of a

presentation which had the

following 9 slides: 1st was a

cover slide introducing the

interviewer and the topic; 2 nd

introduced the rest of the

team (four students and one

faculty member); 3 rd

introduced the research

question (how to integrate

crowdsourcing tasks in design

education?); 4th introduced

what crowdsourcing is -we

referred to Jeff Howe's

definition [7]; 5th reminded

the student of the existing

course's learning goals and

deliverables; 6th presented in

general the crowdsourcing

platform; 7th presented in

detail the crowdsourcing

task; 8th presented in detail a

walkthrough of what is

necessary to complete the

task in the platform; 9th

presented in detail how we

envisioned the crowdsourcing

task replacing the current

assignment. links between crowdsourcing and education, which we review next.

\section{Crowdsourcing and Education}

Early work on the link between crowdsourcing and education identified that there are several dimensions this link can have. For example, educators can apply crowdsourcing methods to deliver personalized education [13]. A recent review of 51 relevant initiatives to the topic of crowdsourcing in education highlighted that crowdsourcing can benefit education in four ways: 1) create educational content; 2) provide practical experience; 3) facilitate the exchange of complementary knowledge and 4) augment feedback [8]. Another interesting work in the topic that was overlooked from the aforementioned review, introduced a simple accounting task from a crowdsourcing platform in a MOOC [3]. In a more visionary paper, researchers have also investigated crowdsourcing platforms offering internships to students who embody the role of a crowd worker [10].

Although prior work has leveraged crowdsourcing in different ways and seems to be quite positive about the role of crowdsourcing in higher education, it crucially has not yet investigated how students would feel and think about replacing one of their existing assignments with a crowdsourcing task. This is a gap in the literature that we would like to address in this paper. More specifically, in this case study we interviewed 24 industrial design students from Eindhoven University of Technology (TU/e) in the Netherlands. With this case study we present some practical implications that design and $\mathrm{HCI}$ educators need to think of before replacing their course assignments with crowdsourcing tasks.

\section{Method}

The aim of our study was to investigate the attitude of university students towards crowdsourcing tasks. How would students feel about completing tasks from a crowdsourcing platform in their course instead of the fictional assignment they are already used to? To address this question, we first thoroughly reviewed the courses we offer at our department and noted the assignments that each course asked students to complete. We then reviewed tasks in crowdsourcing platforms that were currently on offer. Based on the latter review we created 19 different proposals aimed at replacing an assignment that is currently given to students with an actual crowdsourcing task. These proposals had the form of a slideshow presentation (see left column). Each proposal had the same number of slides and the same look and structure. In Figures 1 \& 2 we present examples of slides of such a proposal. Three of these proposals were more general and connected to the competency areas (holistic clusters of knowledge and skills) in our department. The other ones were connected to specific elective courses, which cover a smaller, more specific set of skills and knowledge. These proposals formed the basis of our indepth interviews with students.

Due to time limitations, it was not possible to utilize al the proposals we created. Therefore, we decided to make a selection of three, by rating all the proposals on four criteria: 1) Originality (How original do I find the crowdsourcing (CS) task to be?); 2) Match to the learning objectives (How closely do I think that the CS task matches the course's learning objectives?); 3) Attractiveness of the platform/task (How much do I think that the platform will be attractive for students); 


\section{Selection of the questions we asked $24 \mathrm{TU} / \mathrm{e}$} industrial design students:

- Have you heard of crowdsourcing (CS) before?

- What challenges or opportunities do you foresee in completing this CS task instead of the course assignment?

- What kind of help do you expect from the university when completing this task in this course?

- How do you feel about exposing your design work to the public on a CS platform?

- Do you think the skills gathered from this CS task are useful after you graduate?

- In case you win the CS task, which is in the form of a contest, what should happen to the financial reward?
4) Flexibility (How flexible is the CS task for integration in education?)

Four raters rated all the proposals and based on the weighted average ("match to learning objectives" weighted double in comparison to the other criteria), the best two and the least rated proposal were chosen for further investigation. This was done to see whether the least rated proposal was still good enough to provide reasonable results and thereby play a role in taking the integration of crowdsourcing in education to its fullest potential.

The three proposals became the starting point of our interviews with industrial design students of TU/e. The 24 interviews we conducted lasted roughly twenty minutes each and we audio recorded them. A selection of questions we asked them can be seen on the left column. We exclusively recruited students that had already completed the course, which was part of our integration proposal.

After fully transcribing all 24 interviews, we conducted a thematic analysis [2] over the entire dataset, to identify patterns. More specifically, the data analysis involved the following three steps: data familiarization; thematic framework development; data coding. In the familiarization phase, we carefully went through all transcriptions. The initial thematic framework was based on issues we came across in the related literature and topics that surfaced during the familiarization phase. During the coding stage, we used exact quotes from participants to inductively identify potential themes and patterns within the data, before collating all relevant coded data extracts in the themes we identified.
83. Crowdsourcing Platform: Desall

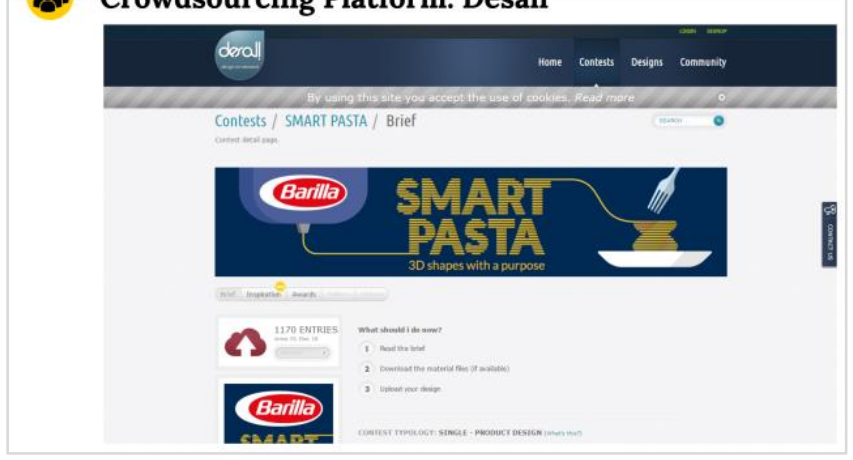

Figure 1: Example of a slide in which we introduced the crowdsourcing platform. In this case it is Desall.com with a competition for creating a 3D model for pasta.

\section{Integration Proposal}

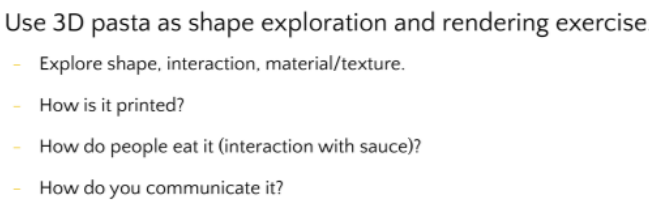

Extracurricular: translate to 3D model (real world practice) Hand in on Desall and maybe get chosen.

Figure 2: Example of a concluding slide that we used in our interviews with students. This specific slide presents a proposal to integrate a task from the crowdsourcing platform Desall.com. The task in the platform requested a sketch, which would be used in a 3D printer for pasta. Our proposal was to leverage this online competition as an assignment in our department's course: Exploratory Sketching. 


\section{The three courses we proposed to replace their current assignments with crowdsourcing tasks:}

1) Digital Craftsmanship, has as learning goals: understanding generative design and practicing CAD/CAM machines. Deliverables include the $3 D$ model and print of a shoe or part of the shoe.

2) Creative Electronics, has as learning goals: understanding elementary circuits \& empowering students to prototype with sensors \& actuators.

Deliverables include weekly exercises, a prototype and a report.

3) Exploratory Sketching, has as learning goals: communicating the design process; exploring designs; becoming confident as designer. Deliverables include weekly sketches and a portfolio at the end.

\section{Results}

We identify four major themes in our data. In this section we present each theme with our participants' quotes to support it.

Theme 1: Current experience with crowdsourcing (CS): Students are essentially unaware of its existence The largest part of our participants did not know what crowdsourcing is and lot of them confused it with crowdfunding: "I don't know exactly what it is. I know that, you know, it's like Kickstarter and you ask people to fund your project, but I don't know specifically." (19year-old male, 2 nd year bachelor's). Although crowdfunding is a form of crowdsourcing, it is certainly not the same since its exclusive objective is to raise funds from the crowd. A minority in our cohort (two students) had in the past contributed to CS platforms: "I actually participated myself in design challenges, just to kind of earn some money, if possible." (19-year-old female, 2nd year bachelor's). The students know that the chance of winning is very small, which can be disappointing. Thus, we can conclude that CS is a largely unknown development in our sample.

Theme 2: Motivations \& Skepticisms In this theme we present the potential pros and cons that our students mentioned when asked to ponder upon replacing an existing assignment with a crowdsourcing task.

Initially, the majority of our students were very enthusiastic about the idea of completing a CS task as an assignment. An indicative quote of a 2 nd year bachelor's female student: "O wow! I think that people (referring to students) get really enthusiastic, because they see probably something they really like."
The most prominent reasons mentioned for being thought as a motivator were: getting to see other's work to get inspiration and learn, getting experience of what would be expected in a professional context, the public competition would stimulate more effort, building up a professional network and getting external recognition to add to one's portfolio.

Two indicative quotes for the last two reasons:

"If you're a student and you do win that challenge, or you get an honourable mention or whatever, it contributes largely to your portfolio, since you won something which you can already show." (20-year-old male, 2nd year bachelor's)

"You get a connection with the real world, and in larger projects, or projects with more, like, clients involved, you have an opportunity to build a network, just like when you would have clients in your design projects." (25 year-old male, 1st year bachelor's).

Additionally, and clearly an important benefit that was recognized by the majority of our participants was their learning experience. More specifically, students thought that contributing to a CS platform will ask for more professional skills, which would be beneficial for their learning process. The students believe that realistic tasks will give them a sense what companies actually look for, within the field of design, and teach them how they can contribute to it with the skills that they have. An indicative quote when a student was asked what such a task would add to a course: "I think having experience from outside of the theory. Breaking free from the theoretic bubble. Because then you get a sense of what companies actually want and expect from designers." (20-year-old female, 2nd year bachelor's) Another student that was asked the same question: "I think it makes it more tangible. Sometimes it's really 


\section{The three crowdsourcing tasks we proposed to replace their current assignments were:}

\section{1) For the Digital} Craftsmanship course: to create generative designs for clothes to be uploaded on Threadless.com.

\section{2) For the Creative}

Electronics course: to program an application for the Hackaday.io open competition.

\section{3) For the Exploratory} Sketching course: to sketch a creative design of a 3D pasta for Barilla's competition at Desall.com. an abstract concept and when you see it really be made and be used by companies, then I think you both have a better match between your skills and the companies' requests." (20-year-old male, 2nd year bachelor's). By applying their skills directly to a real-life case, the purpose of the course is explained with a very practical example that the student can take place in. "I think it's quite interesting that you try to combine the skills that you pick up in a course and immediately apply them to a real case." 7 (19-year-old-male, 3rd year bachelor's); "you can see what you can do in the future, what industrial design is made for" (21-year-old male, 2nd year bachelor's). Because of these aforementioned reasons the students expect that they will have a higher motivation and feeling of purpose, and therefore be more content with their studies.

However, as our interview carried on and while thinking of and discussing the implications of conducting a CS task instead of a fictional course assignment, our participants did raise several issues. The most prominent reasons mentioned for potential costs were: mismatch of CS task with course learning objectives, focus on outcome rather than the process, lack of collaborative work, taking up more time than planned, fear of sharing in public. To further expand on the last point, a possible downside to the competition element that was mentioned, is that students might compare themselves with professional designers on the platform, which could make them feel insecure: "Well, it could also make you perfectionistic and feeling not good enough maybe, because you will probably compare yourself with designers that are much, much better than you are. So it could make you a little bit insecure, I think." (20-year-old female, 2nd year bachelor's)
Theme 3: Students' expectations for support

In this theme we present the answers to our question: "What kind of help do you expect from the university?". Firstly, students mentioned that they would need upfront a clear time schedule and description of the task and the platform. Not every student will know where to begin, or how they are supposed to plan their time. Students will need deadlines and instructions, just as any other course.

Another point that they made was regarding boundaries -i.e. there should be clear boundaries set by the lecturer that determine the uploads a student is allowed to make. The deliverables must also be taken into account in the course's structure. An indicative quote: "I think it's really important to structure the course differently. So that you replace another assignment by this crowdsourcing thing." (20-year-old female 2nd year bachelor's). What the aforementioned student refers to is that some courses do not have typical deliverables. For example, the course Digital Craftsmanship; the end-deliverable for this course is an algorithm, which generates a pattern. The CS platform will need to support the kind of files that this course requires.

Additionally, for some CS tasks the course will need extra learning activities to fully reach the potential of the course's learning goals. An example of an extra activity would be a workshop on how to convert files into different formats. Ideally, CS platforms will need to be able to provide this kind of extra information.

Finally, a less mentioned expectation but crucial for the CS context is legal support. In the words of our participant: "I think legal help, if you want to sell something. I've never sold anything, or put anything on 
a market, so I don't really know if you have to protect your ideas, ..., so we might be able to get help on the parts we're not really focused on, and then we could fully focus on what the course needs to be teaching you." (19-year-old female, 2nd year bachelor's).

Theme 4: What should happen to the reward? The majority of our participants thought that the reward should be shared. In most of the cases our students mentioned at least half of the reward should be given to them with the other half shared with their teachers or the course; i.e. it should be shared with the course teachers to support them in conducting it in the future. Nevertheless, several students emphasized that the experience is more important than the money from winning a CS task: "So the money will be a bonus perhaps, but I'm not sure if it's necessarily a very important addition. I think many people would do it anyway ..., because you took the course that you wanted to" (19-year-old male, 3rd year).

\section{Discussion}

Based on our case study we would like to offer four initial suggestions to educational institutes when they would be interested in integrating crowdsourcing tasks in their educational activities. In the previous sentence, we want to emphasize the adjective "initial" since we strongly believe that these suggestions are in no way exhaustive as further research into the topic is needed.

Suggestion 1: Manage Students' Expectations In our interviews we observed that the majority, if not the entirety of our students were very enthusiastic about the idea of completing a crowdsourcing task instead of a fictional course assignment. But, what might be less expected is that the chance of actually winning a reward is low and the comparison with other work, specially work of professionals, might be tough. Finally, some expectations, such as expanding one's professional network might be too optimistic given the competitive nature of crowdsourcing.

Suggestion 2: Offer Crowdsourcing as an Alternative As crowdsourcing is a new phenomenon and as our students also mentioned several potential costs that might occur when completing a CS task we suggest to universities, after carefully screening potential matching CS tasks, to offer them as an alternative to the existing course assignments. In that way they can reap the benefits and mitigate potential risks.

\section{Suggestion 3: Provide Practical Support}

Crowdsourcing platforms and participating to online competitions is largely unknown for university students. Therefore, we suggest to universities to provide practical support to students in several aspects. Initially in walking them through in creating an account, but also in showing them examples of what they need to upload in the CS platform and in what format. Finally, universities should provide practical advice to both students and teachers when it comes to legal matters.

Suggestion 4: Be Prepared to Share Rewards

In our experience, most higher education institutes have in the core of their IP policy that students' output belongs in its entirety to the institute and not the student or the faculty member. Based on our results, clearly such an IP policy is contradicting students' expectations. Therefore, we suggest sharing the potential rewards with students and faculty members. 


\section{Conclusion}

In an interview study with 24 industrial design students we investigated their opinions on replacing course assignments they had already followed with a matching crowdsourcing task. We report potential benefits and costs and based on our investigation we offer four suggestions to universities that consider integrating crowdsourcing in their educational activities. Future work should eventually research students' actual behavior when offering a CS task. Finally, future work must examine the teachers' point of view as eventually they would have to implement this integration.

\section{Acknowledgements}

We thank TU/e's ID students that assisted us: Felix Ros, Ko Derks, Willem van de Loo, Björn Schulpen, our 24 participating students and TU/e for financially supporting us with the Innovation in Education Grant.

\section{References}

[1] Blumenfeld, P. C., Soloway, E., Marx, R. W., Krajcik, J. S., Guzdial, M., \& Palincsar, A. (1991). Motivating project-based learning: Sustaining the doing, supporting the learning. Educational psychologist, 26(3-4), 369-398.

[2] Braun, V., \& Clarke, V. (2006). Using thematic analysis in psychology. Qualitative research in psychology, 3(2), 77-101.

[3] Chen, G., Davis, D., Krause, M., Aivaloglou, E. Hauff, C., Houben, G. J., \& ICSI, U. B. (2016). Can learners be earners? investigating a design to enable mooc learners to apply their skills and earn money in an online market place. IEEE Transactions on Learning Technologies, 1-12.

[4] Diehl, W., Grobe, T., Lopez, H., \& Cabral, C. (1999). Project-based learning: A strategy for teaching and learning. Boston: Center for youth development and education.

[5] Han, S., Capraro, R., \& Capraro, M. M. (2015) How science, technology, engineering, and mathematics (STEM) project-based learning (PBL) affects high, middle, and low achievers differently: The impact of student factors on achievement. International Journal of Science and Mathematics Education, 13(5), 1089-1113.

[6] Helle, L., Tynjälä, P., \& Olkinuora, E. (2006). Project-based learning in post-secondary education-theory, practice and rubber sling shots. Higher education, 51(2), 287-314.

[7] Howe, J. (2006). The rise of crowdsourcing. Wired magazine, 14(6), 1-4.

[8] Jiang, Y., Schlagwein, D., \& Benatallah, B. (2018). A Review on Crowdsourcing for Education: State of the Art of Literature and Practice. In PACIS.

[9] Kaldi, S., Filippatou, D., \& Govaris, C. (2011). Project-based learning in primary schools: effects on pupils' learning and attitudes. Education 3-13, 39(1), 35-47.

[10] Suzuki, R., Salehi, N., Lam, M. S., Marroquin, J. C., \& Bernstein, M. S. (2016). Atelier:

Repurposing expert crowdsourcing tasks as microinternships. In Proc. CHI 2016 (pp. 2645-2656).

[11] Thomas, J. W. (2000). A review of research on project-based learning.

[12] van Rooij, S. W. (2009). Scaffolding projectbased learning with the project management body of knowledge (PMBOK®). Computers \& Education, 52(1), 210-219.

[13] Weld, D. S., Adar, E., Chilton, L., Hoffmann, R., Horvitz, E., Koch, M., Landay, J., Lin, C.H., \& Mausam, M. (2012). Personalized online education-a crowdsourcing challenge. In Workshops at the 26th AAAI Conference on AI. 